\title{
Publikasi Wahana Wisata Alam Batu Lawang Desa Cupang Kecamatan Gempol Melalui Media Berbasis IT
}

\author{
Tri Budi Prasetyo ${ }^{1}$, Ali Jufri² \\ Universitas Muhammadiyah Cirebon, \\ 1e-mail: tri.budi@umc.ac.id \\ 2e-mail: ali.jufri@umc.ac.id
}

\begin{abstract}
ABSTRAK
Wahana Wisata Alam Batu Lawang Desa Cupang Kec.Gempol melalui Media Berbasis IT dalam memasarkan objek wisata tersebut agar dikenal oleh para wisatawan. Dalam penelitian ini penulis menggunakan metode penelitian melalui teknik pengumpulan data dengan cara observasi, wawancara, study dokumen selama +1 bulan di desa Cupang. Hasil penelitian dan pembahasan menunjukan bahwa Batu Lawang merupakan objek wisata yang mempunyai daya tarik dan potensi yang perlu dikembangkan. Dengan adanya usaha-usaha pembangunan kembali untuk meningkatkan jumlah kunjungan wisatawan.

Dengan keterbatasan tempat atau kawasan yang merupakan salah satu penghambat pembagunan Batu Lawang, usaha-usaha yang lain dengan menambahkan sarana penunjang seperti tempat ibadah, toilet umum, gazebo dan tumbuhan-tumbuhan agar lebih menarik wisatawan yang berkujung ke Batu Lawang. Kesimpulan dari penelitian ini adalah publikasi objek wisata perlu dilakukan untuk mengenalkan potensi-potensi yang dimiliki dan memanfaatkan alam yang terbentuk dengan sendirinya dengan usaha-usaha membagun dan mencari dana bantuan untuk pembagunan agar menjadi objek wisata yang lebih menarik tanpa mengurangi potensi dan mengubah bentuk bagunan aslinya karena memiliki unsur yang indah serta potensi dan keunikan Batu Lawang perlu di lestarikan karena bentuk batu itu terbentuk secara alami sebagai daya tarik wistawan yang berkunjung ke Cirebon.
\end{abstract}

Kata Kunci: Batu Lawang, Cirebon, IT

\begin{abstract}
Wahana Wisata Batu Lawang Desa Cupang, Kec. Gempol through IT-Based Media in marketing the tourist attraction to be known by tourists. In this study, the authors used the research method through data collection techniques using observation, interviews, study documents for +1 month in the village of Cupang. The results of research and discussion show that Batu Lawang is a tourist attraction that has an appeal and potential that needs to be developed. With the rebuilding efforts to increase the number of tourist visits.

With limited places or areas that are one obstacle to the construction of Batu Lawang, other businesses are by adding supporting facilities such as places of worship, public toilets, gazebos, and plants to attract more tourists who end up in Batu Lawang. The conclusion of this research is the publication of tourist attraction needs to be done to introduce the potentials that are owned and utilize nature that formed by itself with efforts to build and seek funding for development to become a more attractive tourist attraction without reducing the potential and changing the shape of the original building because it has beautiful elements as well as the potential and uniqueness of Batu Lawang it needs to be preserved because the shape of the stone is formed naturally it is an attraction for tourists visiting Cirebon.
\end{abstract}

Keywords: Batu Lawang, Cirebon, IT 


\section{PENDAHULUAN}

Berdasarkan Informasi dari Kementrian Pariwisata Republik Indonesia di sebutkan bahwa target wisatawan mancanegara Indonesia telah mencapai angka 8,8 juta dengan laju pertumbuhan wisatawan baik lokal maupun mancanegara sebesar 8,39\% per tahun, atau lebih tinggi dari ratarata pertumbuhan pariwisata dunia sebesar 5\% per tahun. Pencapaian ini tidak dapat terlepas dari perkembangan inovasi teknologi yang semakain dinamis. Perkembangan teknologi dalam bidang informasi secara tidak langsung mendorong pertumbuhan sektor pariwisata, mobilitas wisatawan dan keterbukaan informasi menjadi kunci tren pariwisata masa kini.

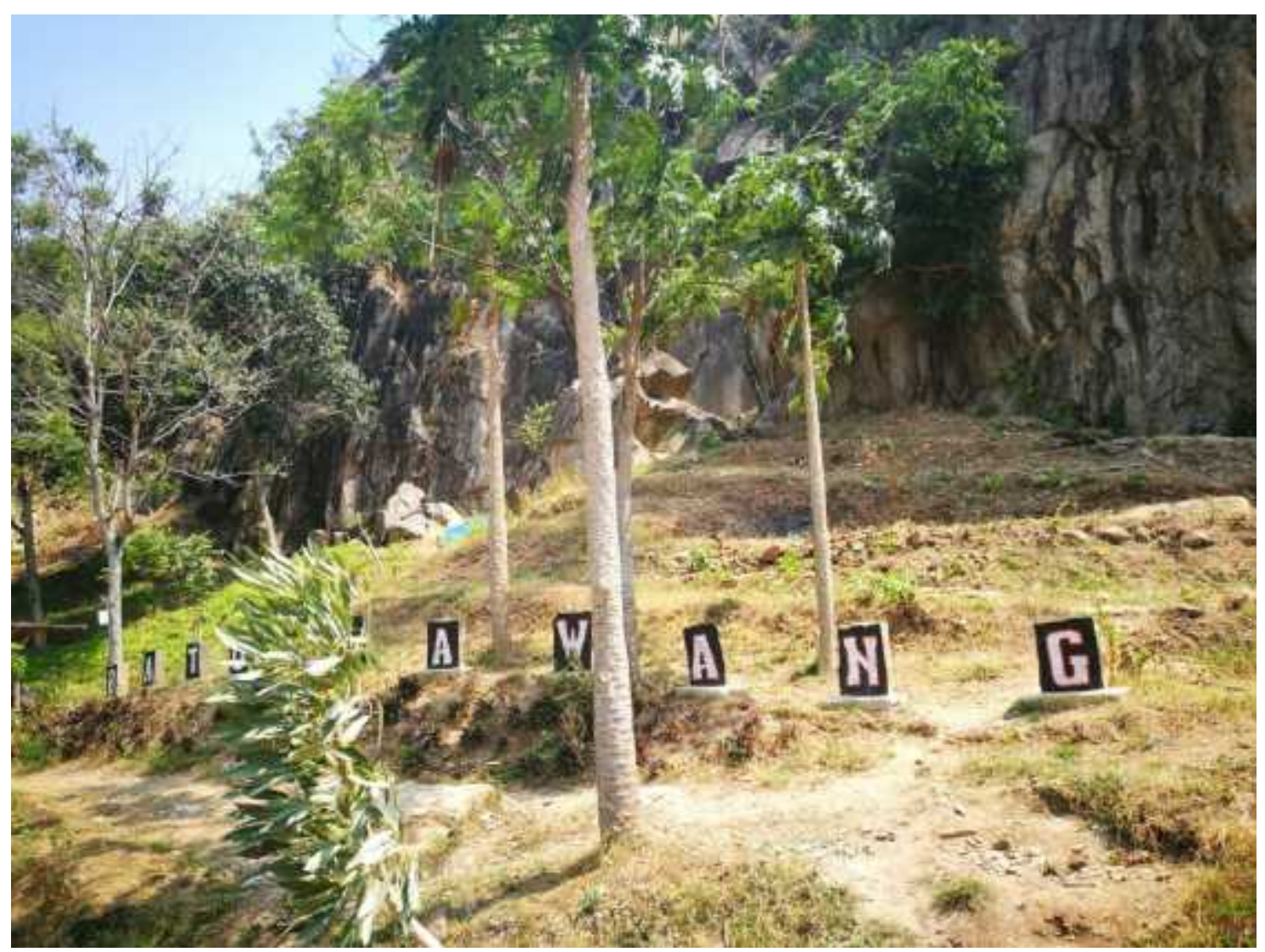

Gambar 1. Kondisi Wisata Alam Batu Lawang

Pengetahuan manusia yang semakin berkembang telah memanfaatkan informasi teknologi untuk mempublikasikan destinasi wisata yang ada disekitar tempat tinggalnya maupun yang pernah dikunjungi. Manusia dengan mudah telah menemukan cara untuk mempublikasikan tempat wisata agar lebih mudah di kenal oleh para wisatawan, melalui informasi Teknologi ini kami ingin mempublikasikan Wahana Wisata Batu Lawang desa Cupang Kec. Gempol melalui media berbasis IT agar para pengunjung tahu bahwa ada wisata alam yang ada di Kota Cirebon. Pada saat ini rata-rata pengujung wisata batu lawang pada hari non weekend 100-200 orang pengunjung 
perhari sedangkan hari weekend pengunjung bisa mencapai tiga kali lipat dari hari biasa kisaran 600-700 orang pengunjung per hari, tidak hanya berfungsi sebagai tempat wisata batu lawang pun kerap kali dijadikan bumi perkemahan yang cukup nyaman karena selain tempatnya yang indah fasilitas yang tersedia juga memadai seperti : Sarana ibadah, Toilet umum, Kantin, Gazebo, serta adanya wahana outbound dan tempat parkir yang luas.

Wisata Alam Batu Lawang itu sendiri terletak di dekat situs patilasan Sunan Bonang yang merupakan destinasi wisata religi (tempat ziarah) bagi para peziarah yang ingin berziarah ke patilasan sunan bonang selain dekat dengan situs Sunan Bonang, wahana wisata alam batu lawang juga dekat dengan destinasi wisata lainnya yaitu Wisata Alam Gunung Jaya yang merupakan bukit yang seringkali dipakai untuk pendakian karena terkenal dengan panorama yang indah diatas bukit tersebut. Wahana Wisata Alam Batu Lawang tersebut dikelola oleh karang taruna desa setempat. Untuk tiket masuk ke tempat wisata alam batu lawang sangat terjangkau, cukup dengan merogoh kocek Rp 5.000,- per/orang wisatawan sudah bisa menikmati keindahan alam wisata batu lawang serta sekaligus sudah mendapat asuransi didalamnya, cukup menarik bukan?

\section{BAHAN DAN METODE}

Publikasi Wisata Alam Batu Lawang ini menggunakan Metode:

Metode persuatif

1. Mengunjungi langsung warga dan perangkat desa untuk menjelaskan bahwa kami akan melakukan Publikasi Wahana Wisata Alam Batu Lawang agar masyarakat luas mengetahui bahwa ada wisata di Desa Cupang melalui IT.

2. Melakukan survey, wawancara maupun pengamatan langsung.

3. Karangtaruna ikut andil dalam memegang akun Instragram untuk publikasi wisata Batu Lawang.

4. Dalam proses penataan tempat wisata alam batu lawang, berkerja sama dengan pihak KWT (Kelompok Wanita Tani) Desa Cupang Kecamatan Gempol, Kabupaten Cirebon 


\section{HASIL DAN PEMBAHASAN}

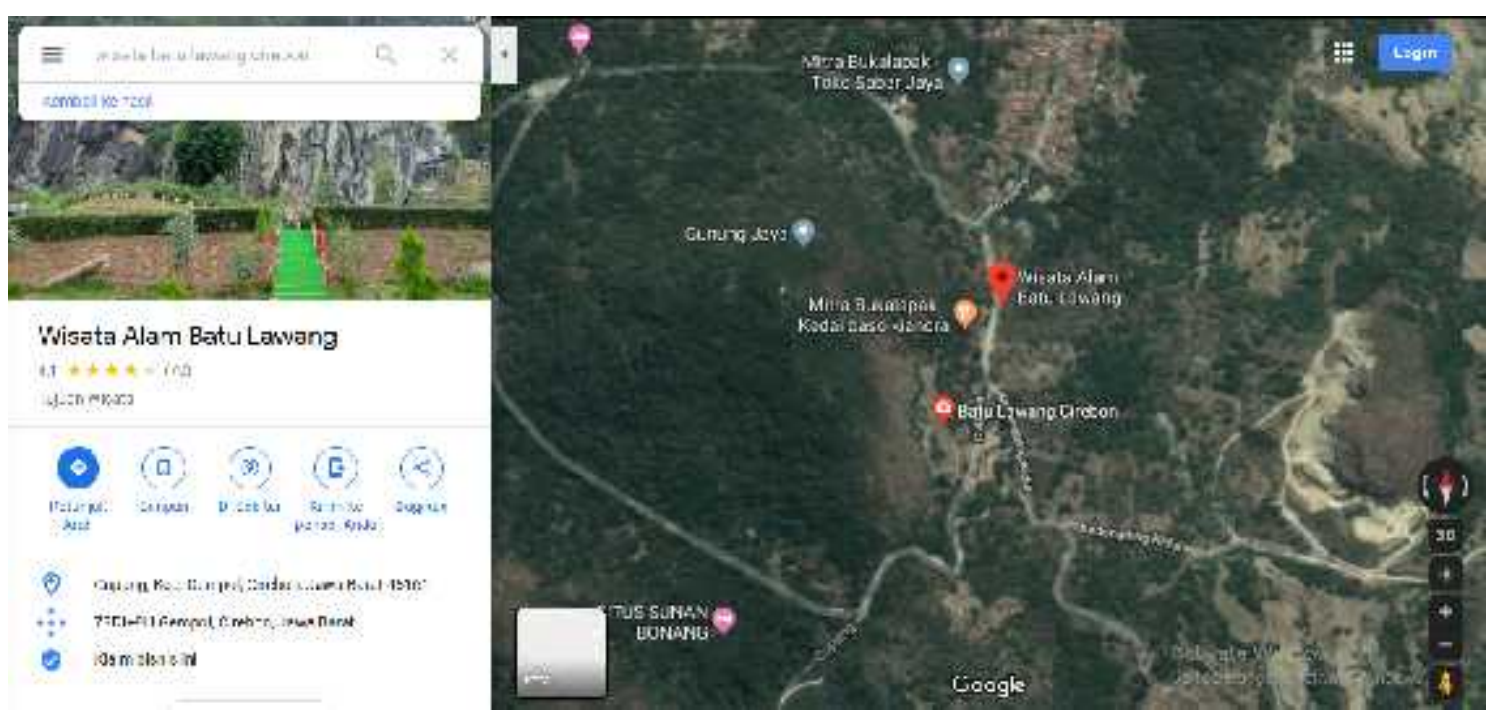

Gambar 2. Lokasi Wisata Batu Lawang

Sumber : https://www.google.com/maps/place/Wisata+Alam+Batu+Lawang

Cirebon? Siapa yang tidak tahu kota Cirebon, kota yang terkenal dengan kota udang. Tapi, saat ini mulai terkuak bahwa banyak tempat wisata alam yang ada di Cirebon. Salah satunya Batu Lawang yang terletak di Desa Cupang. Desa Cupang merupakan sebuah desa yang terletak di Kecamatan Gempol, Kabupaten Cirebon, Jawa Barat, Indonesia. Batu Lawang menjanjikan ketenangan, pemandangan yang indah untuk selfie, setting untuk pre-wedding, video clip, melakukan kegiatan adventure dan hanya untuk sekedar bersantai mencari udara segar. Batu lawang terletak di desa yang cukup terpencil untuk menuju kesana kita harus melewati jalanan yang cukup sulit. Tiket masuk Batu Lawang pun sangat terjangkau yaitu hanya Rp.5.000,- sudah termasuk asuransi.

Meskipun tempat ini terletak jauh dari pusat Kota Cirebon serta akses jalan masuk menuju Wisata Batu Lawang yang sulit namun Wisata Batu Lawang sendiri menjajikan keindahan yang begitu luar biasa, sesudah tiba disana, semua kepenatan serta rasa lelah akan terbayar dengan keindahan pemandangan dari atas. Wisata Batu lawang sangat cocok untuk jalan-jalan bersama keluarga, ataupun dengan teman-teman.

Fasilitas yang ada di Batu Lawangpun sudah sangat lengkap, terdapat Toilet, Gazebo, Sarana Ibadah (Musolla), dan Kantin yang menjajakan aneka jenis makanan sehingga pengunjung tidak binggung jika lapar ataupun ingin beribadah. Untuk mencapai Wisata Batu Lawang $\pm 12 \mathrm{KM}$ / 1 jam dari pusat Kota Cirebon. Nah di puncak bukit, matamu akan di manjakan dengan pemandangan batu-batu galian serta pohon di sekitar yang hijau dan menyehatkan, memiliki alam yang masih terjanga dan kesejukan di sore hari khas pedesaan pikiran akan lebih segar saat main 
ke sini. Batu yang terbentuk dengan sendirinya menyerupai lawang salah satu spot yang menarik untuk berfoto. Beberapa pelancong yang pernah kesini lebih sering berfoto, Cirebon memang terkenal panas tetapi perbukitan Batu Lawang bisa menjadi pilihan untuk berlibur.

\section{Tahap Persiapan}
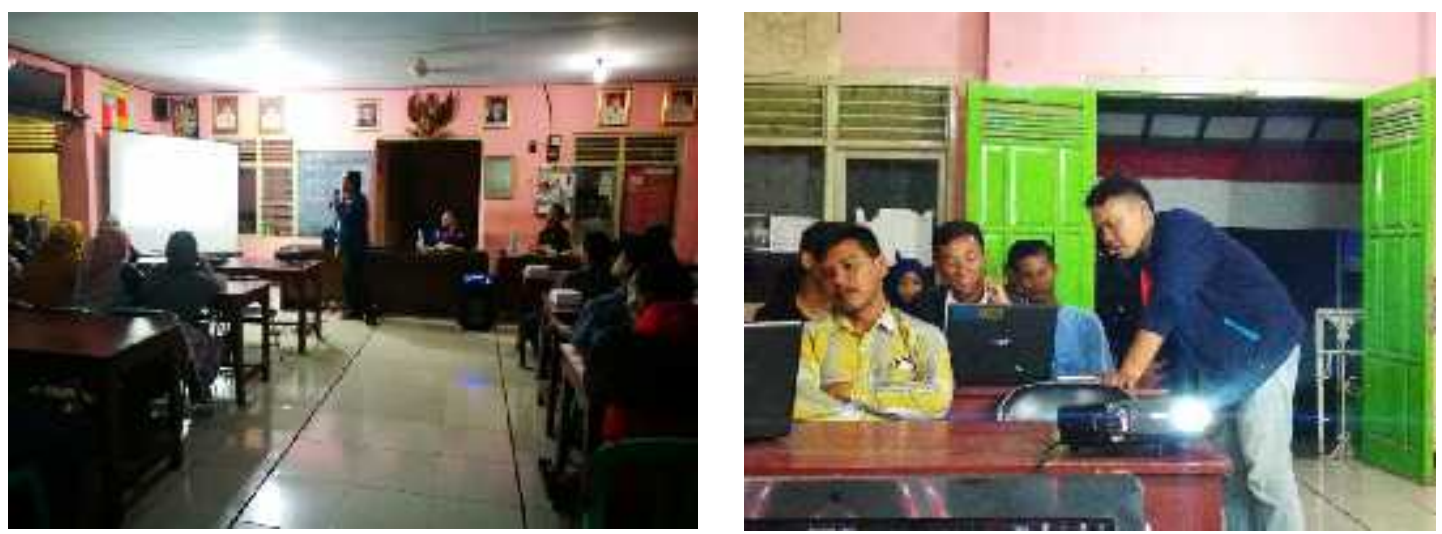

Gambar 3. Tahapan Sosialisasi dengan Karangtaruna dan KWT

(Kelompok Wanita Tani)

Sebelum melakukan Publikasi Wahana Wisata Alam Batu Lawang Desa Cupang Kec. Gempol melalui media berbasis IT, peneliti melakukan tahapan sosialisasi dengan pihak Karangtaruna dan berkerja sama dengan pihak KWT (Kelompok Wanita Tani) yang ada di Desa Cupang Kec. Gempol Kab. Cirebon guna memotret keberadaan Wisata Alam Batu Lawang, sehingga saat melakukan penataan lokasi Wisata Alam Batu Lawang sudah memahami apa yang perlu dilakukan saat ini dan dikemudian hari.

Pelatihan yang dilakukan berkaitan dengan manajemen pengelolaan Wisata Alam Batu Lawang serta pengenalan IT/Sosial Media (Instagram/Facebook) sehingga dikemudian hari dapat melakukan update informasi berkenaan dengan Wisata Alam Batu Lawang.

Adapun penataan yang telah dilakukan dengan pihak Karangtaruna dan berkerja sama dengan pihak KWT (Kelompok Wanita Tani) yang ada di Desa Cupang Kec.Gempol Kab. Cirebon, kondisi bumi perkemahan yang berada di lokasi Wisata Batu Lawang seperti pada gambar dibawah ini. 


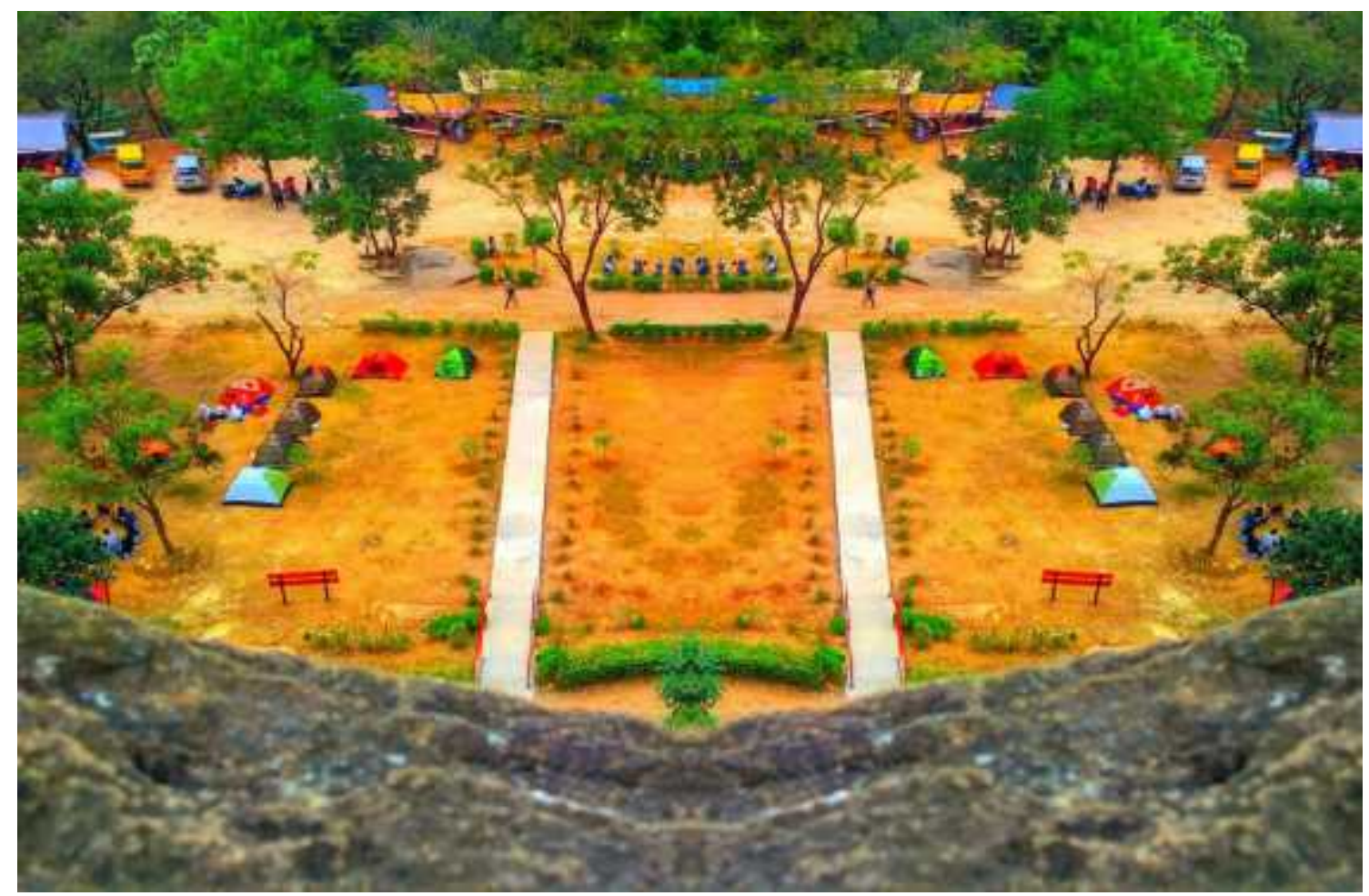

Gambar 4. Lokasi Bumi Perkemahan Wisata Batu Lawang

Selain dari pada itu hasil pelatihan kepada pihak Karangtaruna Desa Cupang Kec.Gempol Kab. Cirebon guna peningkatan pengetahuan tentang IT dalam upaya mempublikasikan Wisata Alam Batu Lawang yang bertujuan masyarakat luas tahu dan tertarik untuk berkunjung ke Wisata Batu Lawang dibuatnya sarana publikasi dengan menggunakan media sosial (Instagram maupun facebook) dapat dilihat pada gambar 5 dan gambar 6.

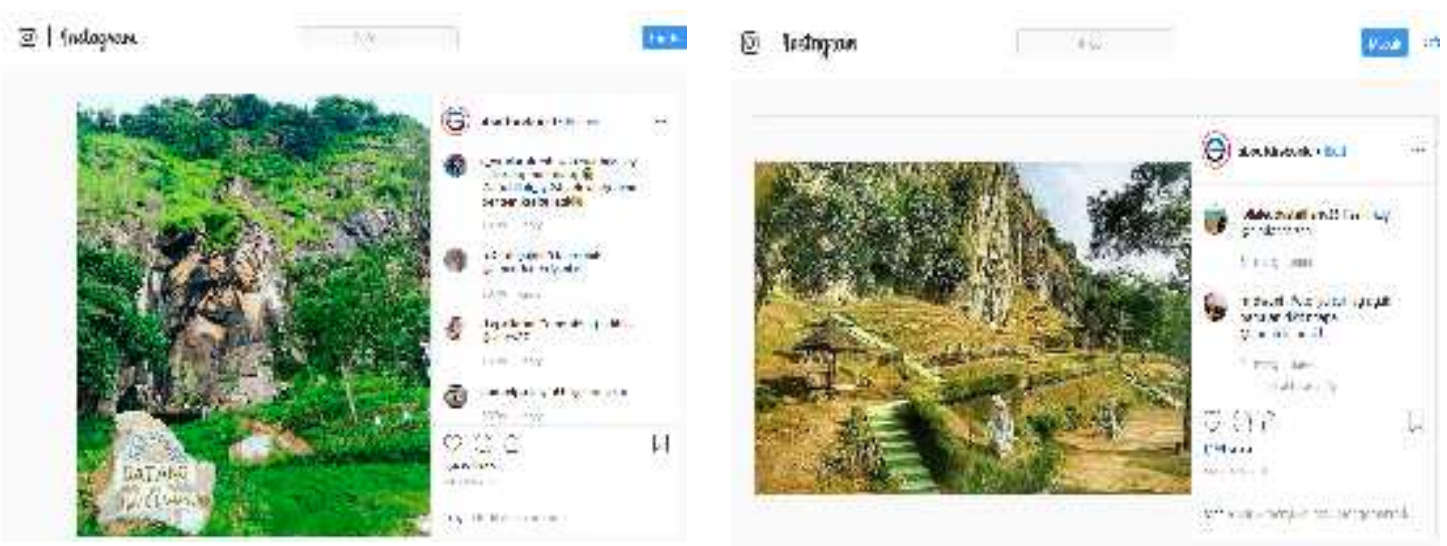

Gambar 5. Instagram Wisata Batu Lawang 


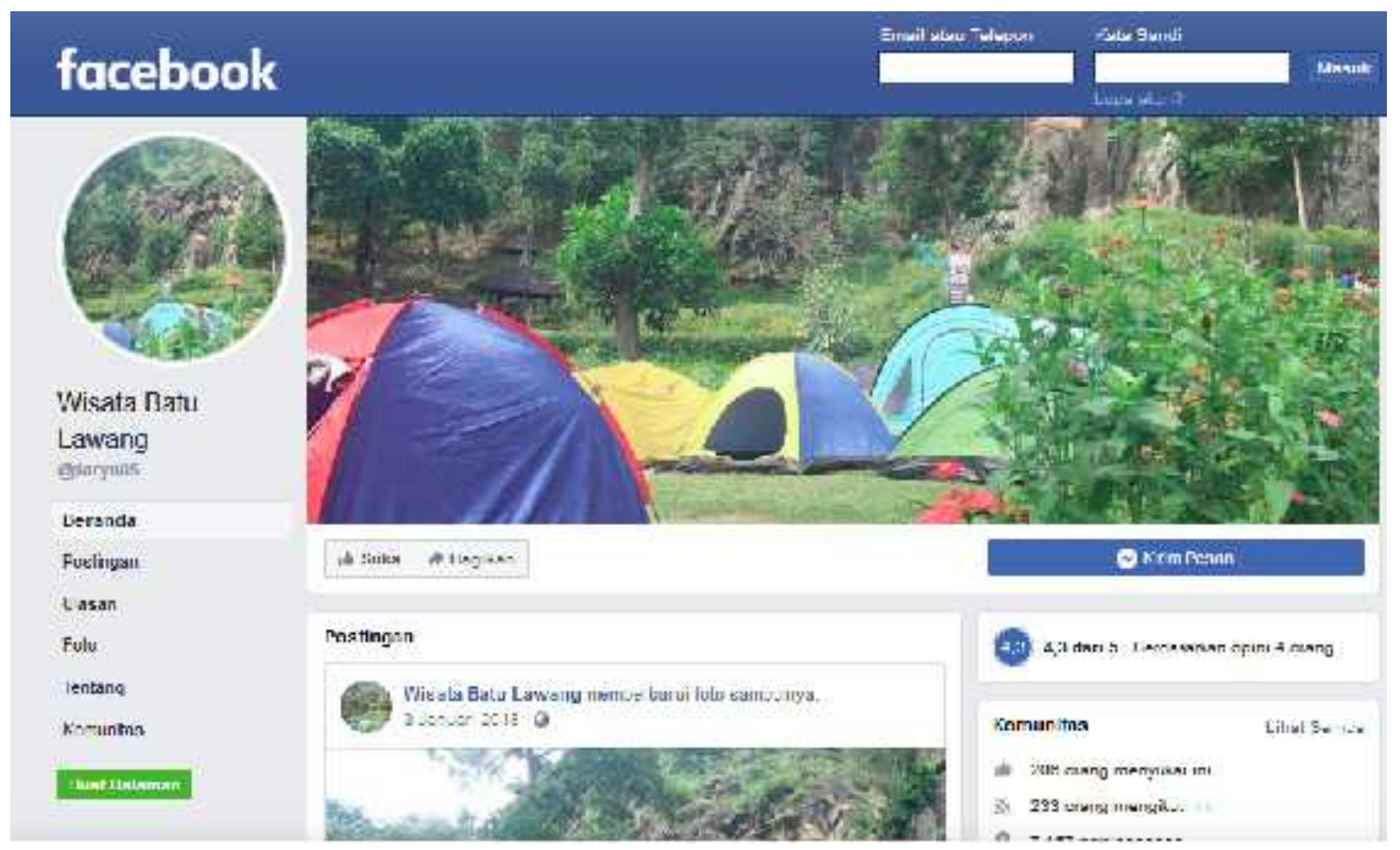

Gambar 6. Facebook Wisata Batu Lawang

\section{KESIMPULAN DAN SARAN}

Publikasi Wisata Alam Batu Lawang melalui media berbasis IT ini sangatlah penting karena untuk mengenalkan wisata baru yang ada di Cirebon, agar masyarakat luas mengetahui dan berkunjung ke Wisata Batu Lawang, dan dilakukan untuk mengenalkan potensi-potensi yang dimiliki dan memanfaatkan alam yang terbentuk dengan sendirinya dengan usaha-usaha membagun dan mencari dana bantuan untuk pembagunan agar menjadi objek wisata yang lebih menarik tanpa mengurangi potensi dan mengubah bentuk bagunan aslinya karena memiliki unsur yang indah. Sasaran program kegiatan Publikasi Wahana Alam Batu Lawang berbasis IT ini untuk mengali potensi-potensi dan keunikan Batu Lawang itu sendiri, dan Batu Lawang perlu di lestarikan karena bentuk batu itu terbentuk secara alami tanpa di buat atau di ukir dan dikembangkan secara optimal karena sebagai daya tarik wistawan yang berkunjung ke Cirebon.

\section{UCAPAN TERIMA KASIH}

Ucapan terima kasih penulis sampaikan kepada:

1. Perangkat Pemerintah Desa Cupang Kec. Gempol Kab. Cirebon

2. Karang taruna Desa Cupang Kec.Gempol Kab. Cirebon

3. Kelompok Wanita Tani (KWT) Desa Cupang Kec.Gempol Kab. Cirebon 